\title{
Small bowel radiation enteritis diagnosed by capsule endoscopy
}

\author{
John Schembrii, ${ }^{1}$ Matthias Azzopardi, ${ }^{2}$ Pierre Ellul ${ }^{3}$
}

${ }^{1}$ Department of Medicine, Department of Health, Msida, Malta

${ }^{2}$ Department of Medicine, Mater Dei Hospital, Msida, Malta

${ }^{3}$ Department of Gastroenterology, Mater Dei Hospital, Msida, Malta

\section{Correspondence to} Dr John Schembri, john.c.schembri@gmail.com

Accepted 27 January 2014
CrossMark

To cite: Schembri J Azzopardi M, Ellul P. BMJ Case Rep Published online: [please include Day Month Yearl doi:10.1136/bcr-2013202552

\section{DESCRIPTION}

Our patient is a middle-aged woman who had been diagnosed with uterine leiomyosarcoma for which she underwent total abdominal hysterectomy with bilateral salpingo-oophorectomy. She received adjuvant radiotherapy which was delivered over a period of 4 weeks and which involved 20 fractions of $225 \mathrm{cGy}$ each for a total of $4500 \mathrm{cGy}$, followed by a further two courses of pelvic radiotherapy in view of local recurrence.

She presented to us with severe transfusiondependent anaemia associated with loose stools and abdominal pain 1 year after initial surgery. Abdominal CT and oesophagogastroduodenoscopy were normal and a colonoscopy revealed large stains with fresh blood and small clots on normal mucosa in the caecum and ascending colon. Since the impression was that the source of bleeding was from the small intestine the patient was thus scheduled to have video capsule endoscopy (VCE) after ensuring that there was no retention of the patency capsule.

VCE revealed patches of mucosal atrophy and villous oedema (figure 1), stricturing (figure 2) as well as diffuse bleeding from the terminal ileum (figure 3). The gastrointestinal epithelium has a high proliferation rate, which makes it susceptible to damage by radiotherapy more than surrounding tissues. Radiation enteritis can be both acute and chronic, the latter typically developing $8-12$ months after radiation exposure secondary to an obliterative arteritis. The small bowel becomes thickened with obstruction of lymphatics which results in mucosal and villous oedema. Intestinal mucosa becomes

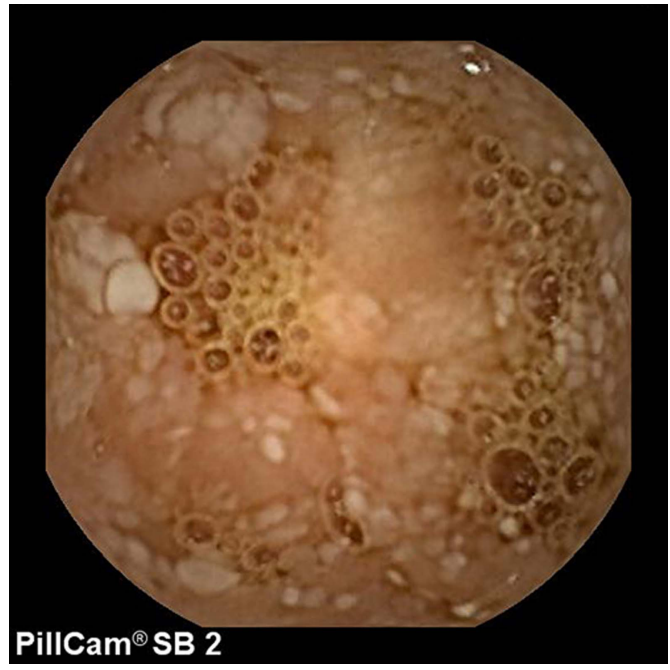

Figure 1 Still capsule endoscopy image showing patches of whitish swollen villi with blunting of others.

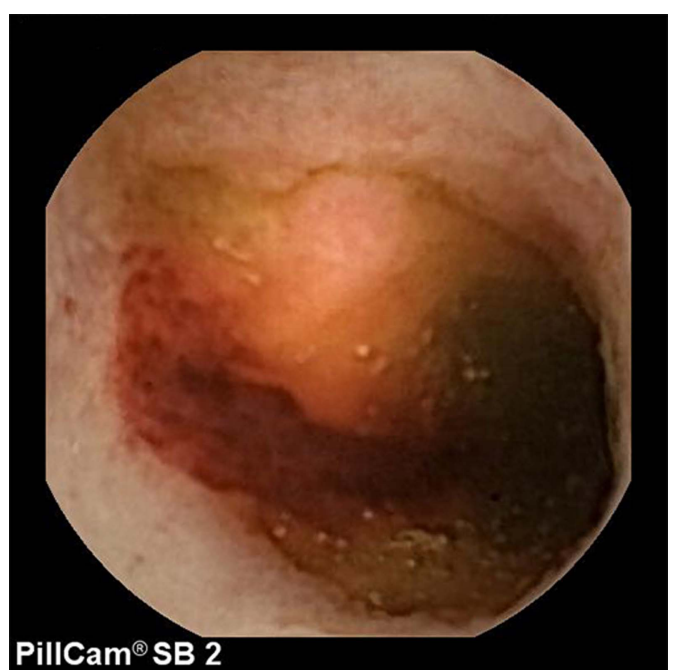

Figure 2 Still capsule endoscopy image showing stricturing of jejunal lumen.

atrophied and bleeding can result from telangiectasias or from mucosal ulcerations. The latter will heal by fibrosis and lead to narrowing of the lumen and stricture formation. ${ }^{1}{ }^{2}$ All these findings were present in our patient and together with the history of radiation exposure the diagnosis of chronic radiation enteritis was made.

To date published experience with regard to the use of VCE in small bowel enteritis is mainly anecdotal. The largest study, which involved 15 patients, concluded that VCE can safely and effectively diagnose small intestinal radiation enteritis

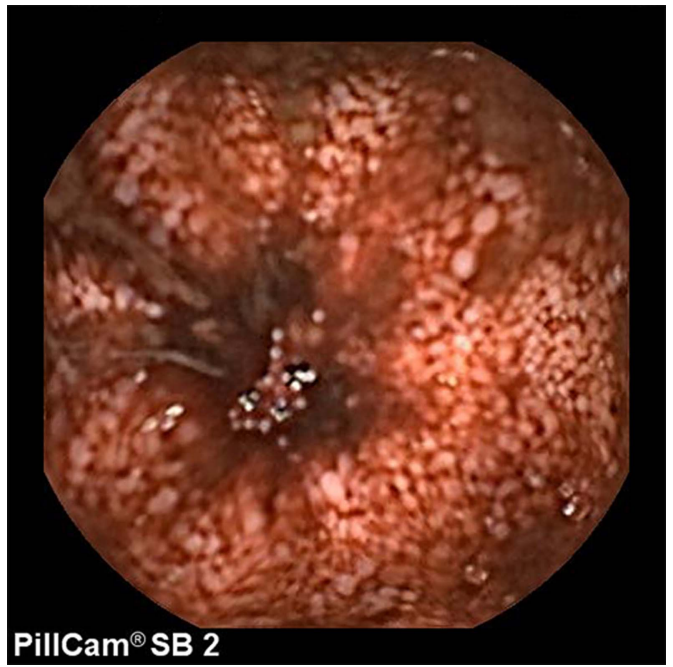

Figure 3 Still capsule endoscopy showing oozing of blood from mucosal surface of terminal ileum. 
and reported no episodes of capsule retention. The most common finding was that of mucosal and villous oedema. ${ }^{2}$ Despite this, various other case reports have described capsule retention usually requiring surgical intervention, with some authors suggesting that a history of abdominal or pelvic radiotherapy should be a relative contraindication to VCE. ${ }^{3}$ Until more robust evidence becomes available one should treat suspicion of small intestinal radiation enteritis with caution, as for any other stricturing disease, and take all appropriate measures. In our case this involved the prior administration of a patency

\section{Learning points}

- Despite reports of capsule retention, capsule endoscopy remains an effective and safe way of diagnosing radiation enteritis, especially if involving the small bowel and if other means of investigation have failed at achieving diagnosis.

- Complications related to radiation enteritis can occur up to 1 year after radiation exposure.

- Treatment of radiation enteritis is usually focused on symptom relief and management of complications. The condition is often progressive and prognosis is related to underlying cancer recurrence. capsule and regular follow-up to ensure passage of the patency capsule.

Our patient responded well to a short course of methylprednisolone and transfusion requirements have significantly improved since then. Experience with specific medical treatments has been derived largely from small clinical trials and case series and surgical intervention should be avoided as much as possible. Some authors describe the use of transendoscopic ablative techniques to control bleeding foci; however, in our case this was not possible since bleeding was diffuse and not arising from single identifiable lesions.

Contributors JS contributed to literature review and formatting; MA to patient follow-up and literature review; PE to picture acquisition and interpretation and final approval.

Competing interests None.

Patient consent Obtained.

Provenance and peer review Not commissioned; externally peer reviewed.

\section{REFERENCES}

1 Schofield PF, Carr ND, Holden D. Pathogenesis and treatment of radiation bowel disease: discussion paper. J $R$ Soc Med 1986;79:30.

2 Kim HM, Kim YJ, Kim HJ, et al. A pilot study of capsule endoscopy for the diagnosis of radiation enteritis. Hepatogastroenterology 2011;58:459-64.

3 Rogers AM, Kuperman E, Puleo FJ, et al. Intestinal obstruction by capsule endoscopy in a patient with radiation enteritis. JSLS 2008;12:85-7.

Copyright 2014 BMJ Publishing Group. All rights reserved. For permission to reuse any of this content visit http://group.bmj.com/group/rights-licensing/permissions.

BMJ Case Report Fellows may re-use this article for personal use and teaching without any further permission.

Become a Fellow of BMJ Case Reports today and you can:

- Submit as many cases as you like

- Enjoy fast sympathetic peer review and rapid publication of accepted articles

- Access all the published articles

- Re-use any of the published material for personal use and teaching without further permission

For information on Institutional Fellowships contact consortiasales@bmjgroup.com

Visit casereports.bmj.com for more articles like this and to become a Fellow 